Research Article

\title{
Real-Time Application Optimization Control Algorithm for Energy Management Strategy of the Hybrid Power System Based on Artificial Intelligence
}

\author{
Yanying $\mathrm{Ma}^{1}$ and Qiang Liu $\mathbb{D}^{2}$ \\ ${ }^{1}$ Faculty of Applied Sciences, Jilin Engineering Normal University, Changchun 130052, Jilin, China \\ ${ }^{2}$ School of Automotive Engineering, Jilin Engineering Normal University, Changchun 130052, Jilin, China \\ Correspondence should be addressed to Qiang Liu; liuqiang@jlenu.edu.cn
}

Received 25 August 2021; Revised 28 September 2021; Accepted 13 October 2021; Published 8 November 2021

Academic Editor: Sang-Bing Tsai

Copyright (C) 2021 Yanying Ma and Qiang Liu. This is an open access article distributed under the Creative Commons Attribution License, which permits unrestricted use, distribution, and reproduction in any medium, provided the original work is properly cited.

In recent years, due to the strengthening of our country's comprehensive strength, the rapid development of science and technology and artificial intelligence has also attracted people's attention. Artificial intelligence is a highly applicable subject, which has very good applications in power systems. In the experiment, the open circuit voltage method and the ampere-hour integration method are used to estimate the SOC of the lithium battery and the particle swarm energy management algorithm is used to allocate the output power of the fuel cell and the lithium battery. The particle swarm algorithm module calls the dual source hybrid power system module through the sim function to convert the actual value input in the system into a fuzzy quantity suitable for fuzzy control. The energy management strategy based on particle swarm optimization and fuzzy control was tested based on working conditions under the comprehensive test bench. Finally, the matching of the hybrid system is analyzed from the structure, component parameters, control strategy, and driving cycle of the vehicle. The experimental data show that the total fuel consumption of the three sets of experiments is averaged to get a fuel consumption rate of $26.3 \mathrm{~m}^{3} / 100 \mathrm{~km}$ for the hybrid city bus under the optimized energy management strategy. The results show that the real-time energy management strategy based on particle swarm algorithm can significantly improve the real-time performance of traditional instantaneous energy management strategies while reducing fuel consumption.

\section{Introduction}

Due to the increasingly serious problems of energy shortage and environmental pollution, modern urban transportation needs a new type of transportation with energy saving and low pollution. Hybrid electric vehicles have the characteristics of long cruising range, low fuel consumption rate, and low emissions. Therefore, hybrid electric vehicles are one of the effective ways to realize vehicle energy saving and emission reduction. Power parameter matching and energy management strategies are the core technologies of hybrid electric vehicles, and their quality directly affects the vehicle's power, economy, and emissions. Energy is an important factor restricting the sustainable and healthy development of China's economy and society. The fundamental way to solve the energy problem is to adhere to the principle of simultaneous development and conservation and putting conservation in the first place, vigorously promote energy conservation and consumption reduction, and improve energy utilization efficiency.

Fuel cell vehicles and EV are the same in that they do not produce harmful gases during vehicle driving. Usually, hydrogen and methanol are used as fuel, which reacts with oxygen in the power cell to generate electricity and drive the motor to output power. It has the advantages of small volume, zero emission, and fast charging.

In fact, articles related to the real-time application of energy management strategies for hybrid power systems based on artificial intelligence are not uncommon at home and abroad. Many experts and scholars have begun to 
conduct in-depth research in this area. Ettihir introduced the energy management strategy (EMS) of fuel cell hybrid electric vehicles (FC-HEV). His goal is to take into account the working conditions of the FCS and ensure the best power distribution between the fuel cell system (FCS) and the battery pack. FCS is a multiphysics system; therefore, its high-energy performance depends on operating conditions. He must use specific techniques to achieve the best performance of FCS. He uses the adaptive recursive least squares (ARLS) method to find models online to find changes in FCS performance. Then, he used optimization algorithms on the updated model to find the best efficiency and power operating point. Although his research is effective, it is not accurate enough [1]. Cao uses effective analysis tools and adaptive simplified human learning optimization (ASHLO) algorithm to solve the optimal power flow (OPF) problem in the AC/DC hybrid power system. His research method is less innovative [2]. Bizon proposed a new energy management strategy for hybrid power systems based on proton exchange membrane fuel cell systems as backup energy sources to reduce hydrogen consumption. He uses the load demand on the DC bus to follow the control loop and optimize the control loop to improve fuel economy based on the global extreme value search algorithm applied to the air flow rate. He compared the performance of the proposed strategy with the strategy obtained through a static feedforward strategy, in which three case studies were considered. These optimization functions were used for the power flow on the DC bus in different situations. His research lacks necessary data [3]. Mahto believes that the highly intermittent power generated by wind energy in an isolated hybrid system (IHPS) can cause severe frequency and power fluctuations. He adopted the IHPS model, including diesel generators, wind generators, and energy storage devices. He optimized and adjusted the different adjustable parameters considered in order to suppress the frequency and power of the IHPS model due to changes in load demand through the quasialignment harmony search (QOHS) algorithm. He also conducted robust and nonlinear research on the configuration of the studied IHPS model based on the SF-FLC-PID controller. The factors considered in his research are not comprehensive [4].

In this paper, the current road surface is identified according to the characteristics of vehicle driving. According to the identified road surface, the corresponding electric braking force distribution method is proposed, which makes the vehicle recover more braking energy on the high adhesion road and less on the low adhesion road on the premise of ensuring safety and improves the overall braking energy recovery rate of the vehicle.

\section{Hybrid Power System and Energy Management Strategy}

2.1. Overview of Artificial Intelligence. Artificial Intelligence refers primarily to the use of computers to mimic the human brain and the use of computers to replace the distinctive functions of human technology [5]. The field of artificial intelligence research, including robotics and image recognition, is relatively broad. HSD (Hybrid Power System) technology belongs to strong hybrid power. The difference from weak hybrid power that cannot drive the vehicle with pure electric power is that it allows the vehicle to run in pure electric mode. HSD technology combines electric drive and planetary gear technology at the same time to achieve a similar effect to a continuously variable transmission. In vehicles equipped with HSD technology, whether it is the accelerator pedal or the gear position, the purpose of control is achieved by sending electronic signals to the control computer. A good energy management strategy can make it better to achieve this goal.

2.2. Hybrid System. In hybrid vehicles, because the ISG motor torque can be used to adjust the operating point of the engine, the efficiency of the hybrid power system is improved and the fuel consumption can be reduced. When the required torque of the vehicle is low, the ISG motor generates electricity, converts the mechanical energy into electrical energy, and stores it in the power battery to increase the output torque of the engine; when the required torque of the vehicle is high, the ISG motor is electric, and the electric energy in the power battery is converted into mechanical energy, reducing the torque of the engine. At the same time, when the hybrid vehicle is running at a lower speed or with a lower load and sufficient battery power, the ISG motor can be used to drive the vehicle alone [6,7]. The energy management system starts from the whole process of the system, follows the principles of system management, and establishes a complete, effective, and documented energy management system within the organization through the implementation of a complete set of standards and specifications, focusing on the establishment and implementation of process control, to continuously optimize the organization's activities, processes, and elements, through routine energy-saving monitoring, energy audits, energy efficiency benchmarking, internal audits, organization of energy consumption measurement and testing, organization of energy balance statistics, management review, self-evaluation, and energy-saving technological transformation, energy-saving assessment, and other measures to continuously improve the effectiveness of the continuous improvement of the energy management system, realize the energy management policies and commitments, and achieve the expected energy consumption or use targets.

Ignoring the lateral dynamic model of the vehicle, given the vehicle speed $V$ and slope $\alpha$, the driver's required torque on the wheel can be calculated from the longitudinal dynamic model of the vehicle:

$$
T_{\text {req }}=r\left(\frac{C_{D} A v^{2}}{21.15}+f m g \cos \alpha+m g \sin \alpha+\delta \frac{\mathrm{d} v}{\mathrm{~d} t}\right)
$$

Among them, $r$ is the wheel radius, $C_{D}$ is the air resistance coefficient, and $m$ is the car mass.

The required torque $T_{\mathrm{dem}}$ at the input of the gearbox is 


$$
T_{\text {dem }}= \begin{cases}\frac{\left.T_{\text {req }}+T_{\text {loss }}\left(\omega_{w}, g\right)\right)}{R(g) \eta(g)}, & T_{\text {req }}+T_{\text {loss }} \geq 0, \\ \frac{T_{\text {req }}+T_{\text {loss }}\left(\omega_{w}, g\right)}{R(g)} \eta(g), & T_{\text {req }}-T_{\text {loss }}<0 .\end{cases}
$$

Among them, $T_{\text {loss }}\left(\omega_{w}, g\right)$ is the additional loss caused by friction, $R(g)$ is the total gear ratio, and $g$ is the corresponding gear ratio.

The wheel angular velocity can be calculated by the following formula:

$$
\omega_{w}=\frac{(1+s) v}{r(v)}=\frac{\omega_{\text {in }}}{R(g)} .
$$

Among them, $s$ is the tire slip rate. It can be concluded from the vehicle motion equation:

$$
\omega_{w}(t+1)=\omega_{w}(t)+\frac{T_{w}(t)-B_{w} \omega_{w}(t)-r\left(F_{r}+F_{a}\right)}{\left(m+m_{r}\right) r^{2}} .
$$

Among them, $B_{w}$ is the air viscosity coefficient, $F_{r}$ is the rolling resistance, $F_{a}$ is the air resistance, and $m_{r}$ is the effective mass of the rotating parts of the vehicle [8].

Since each node is equipotential, the potential of any node can be expressed by the Nernst equation:

$$
E_{\text {cell }}=E_{i}=E_{\text {nernst }}-E_{\text {act }}-E_{\text {conc }}-E_{\text {ohm }} \text {, }
$$

where $E_{\text {cell }}$ is the external voltage provided by the monolithic battery, $E_{i}$ is the potential of the $i$-th node, and $E_{\text {nernst }}$ is the cell Nernst potential, that is, the open circuit voltage of the cell [9]. The following three formulas are the battery capacity of formula (5), where act is synonymous with the small capacity of the battery, conc is synonymous with the medium capacity of the battery, and it should be noted that ohm is the synonym for the large capacity of the battery.

Nernst potential expression is

$$
E_{\text {Nernst }}=E_{0}+\frac{2 F}{R t_{P E N}} \ln \left(\frac{P_{\mathrm{O}_{2}}^{1 / 2} P_{\mathrm{H}_{2}}}{P_{\mathrm{H}_{2} \mathrm{O}}}\right) \text {. }
$$

When the vehicle climbs the slope, it suffers from air resistance, rolling resistance, and slope resistance, which are expressed as follows:

$$
F_{t}=F_{f}+F_{w}+F_{i} .
$$

Then, the calculation formula of vehicle gradeability is

$$
\alpha=\arcsin \left(\frac{F_{t}-C_{D} A v^{2} / 21.15}{m g \sqrt{1+f^{2}}}\right)-\operatorname{arctg}(f) .
$$

The battery capacity is adjusted by changing the number of modules in series. In this process, the impact of battery quality changes on the quality of the entire vehicle must be fully considered [10]. The mathematical formula of battery energy required for pure electric driving distance can be expressed as follows:

$$
E_{b}=\frac{\int_{0}^{T} P_{r} \mathrm{~d} t}{\left(\mathrm{SOC}_{\max }-\mathrm{SOC}_{\min }\right) \eta T}
$$

where $E_{b}$ is the required battery energy and $T$ is the total travel times.

In this paper, the influence of temperature on the battery pack is ignored, and the internal resistance model is used to model the battery pack.

$$
\operatorname{SOC}(t+1)=\operatorname{SOC}(t)-\frac{V_{\mathrm{OC}}-\sqrt{V_{\mathrm{OC}}^{2}-4 R_{\mathrm{int}} T_{m}(t) \omega_{m}(t) \eta_{m}^{-\operatorname{sgn}\left(T_{m}\right)}}}{2\left(R_{\mathrm{int}}+R_{t}\right) Q_{\max }} .
$$

Among them, $V_{\mathrm{OC}}$ is the open circuit voltage of the battery, $R_{\text {int }}$ is the internal resistance of the battery, and $T_{m}(t)$ is the motor torque at time $t$.

The CAN topology design of hybrid electric vehicle is shown in Figure 1. The vehicle controller not only is the control core of the power system, but also needs to interact with the body accessories system. For example, the vehicle controller needs to communicate with the antilock brake system to reasonably control the vehicle torque $[11,12]$.

2.3. Energy Management Strategy. The power balance relationship of lithium battery SOC is as follows:

$$
P_{t}=P_{f c}+P_{b a}
$$

According to the designed dynamic planning process of energy management strategy, the dynamic programming algorithm program is designed based on MATLAB software platform, including four parts: discretization processing, determination of reachable state set, calculation of fuel consumption matrix, and solution of energy distribution trajectory [13].

(1) Discretization. Considering that the update frequency of driving cycle speed is $1 \mathrm{~s}$, the time to walk length is set as $1 \mathrm{~s}$; the SOC discrete grid is equidistant grid, and its size is determined according to the battery capacity $(0.01 \%$ for the model battery discrete grid of prototype vehicle). With the increase of battery capacity, in order to make the corresponding electric power value of each grid change basically unchanged and ensure the calculation accuracy, the SOC grid size should be appropriately reduced [14].

(2) The reachable state set is determined. In the process of optimization calculation, due to the existence of system constraints and the limitation of battery working range, the working range of power system in the whole driving cycle is bounded.

$$
P_{\text {EM }}(k)=P_{\text {req }}(k)-P_{\text {ICE, } \max }(k) \text {. }
$$

The corresponding maximum charge and discharge power of the battery can be written as 


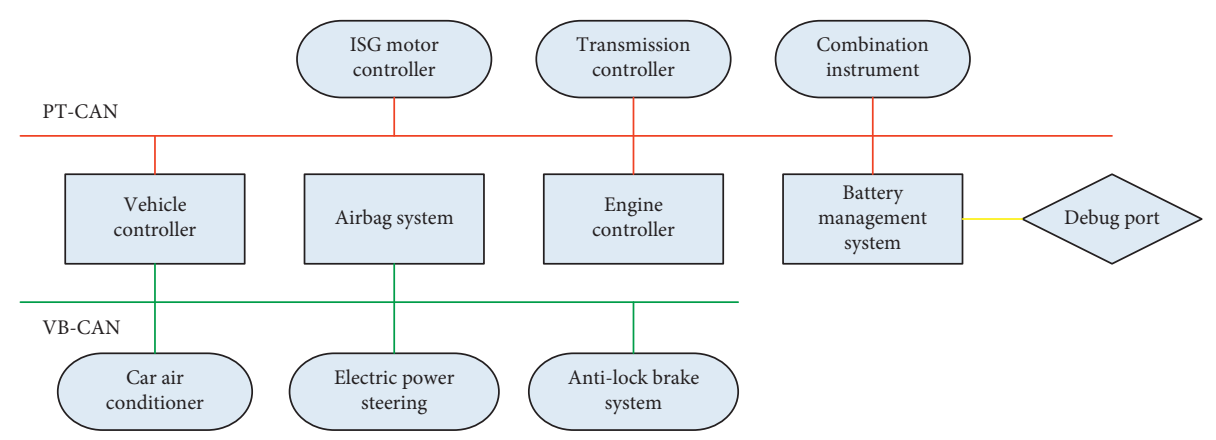

Figure 1: CAN topology design for hybrid electric vehicles.

$P_{\text {batt }}(k)= \begin{cases}\frac{-P_{\mathrm{EM}}(k)}{\left(\eta_{\mathrm{EM}}(k) \times \eta_{C}\right)}, & P_{\mathrm{EM}}(k) \geq 0, \\ P_{\mathrm{EM}}(k) \times \eta_{\mathrm{EM}}(k) \times \eta_{C}, & P_{\mathrm{EM}}(k)<0 .\end{cases}$

Here, $P_{\text {req }}(k)$ is the required power.

(3) Fuel consumption matrix calculation. On the premise that the required power is known, the power (torque) of the corresponding engine can be calculated according to the power balance principle. Finally, the fuel consumption value can be obtained by looking up the table with the established engine fuel consumption model (static fuel consumption map)
[15]. The fuel consumption calculation of stage $k$ is described as follows:

$$
\begin{aligned}
L(x(k), u(k)) & =\text { fuel }(k) \\
& =\frac{f_{1}\left(n_{\mathrm{ICE}}(k), T_{\mathrm{ICE}}(k)\right) \times P_{\mathrm{ICE}}(k)}{3600 \rho} .
\end{aligned}
$$

Among them, $x(k)$ is the set of feasible state points of the power source speed (vehicle speed) and battery SOC in the $k$-th stage.

(4) Energy distribution trajectory solution. The recursive call equation established is as follows:

$$
J_{N-1}^{*}(\operatorname{SOC}(N-1))=\min _{u(N-1)}\left[\operatorname{fuel}\left(\operatorname{SOC}(N-1), T_{\mathrm{EM}}(N-1), T_{\mathrm{ICE}}(N-1)\right)\right]
$$

2.4. Optimized Control Algorithm. As the basis for studying energy management control strategies, the parameter matching of hybrid electric vehicle power systems not only affects the formulation of the strategy, but also determines the performance of the entire vehicle. At the same time, there is a certain coupling relationship between the parameter matching of key components and the energy management strategy. In the objective function composed of economy and vehicle manufacturing cost, when the parameters that affect the two are jointly optimized, the choice of optimization variables is particularly important $[16,17]$.

The basic core of particle swarm optimization (PSO) is to make use of the information shared by individuals in the group, so that the whole population can continuously search for the optimal individual in the solution space and carry out search iteration, so as to obtain the optimal solution of the problem. The flow of the algorithm is as follows:

(1) A group of random particles are generated; each particle is given the corresponding initial position and velocity.
(2) According to the problems to be solved, the corresponding optimization objective function is formulated, which is called fitness function in professional terms, and the fitness value of each particle is calculated through the fitness function.

(3) The fitness value of each particle is compared with that of its current optimal position.

(4) The fitness value of each particle's current optimal position is compared with that of the global optimal position. If there are particles more in line with the optimization goal, the position is recorded as the global optimal position.

(5) Judge whether the iteration meets the termination condition of particle swarm optimization [18].

The control process of model predictive control is shown in Figure 2. The MPC controller optimizes the solution according to the above principle to obtain the optimal control quantity at each time, and the control signal is transmitted to the controlled system, and then the state observation $x(t)$ of the system at each time is input 


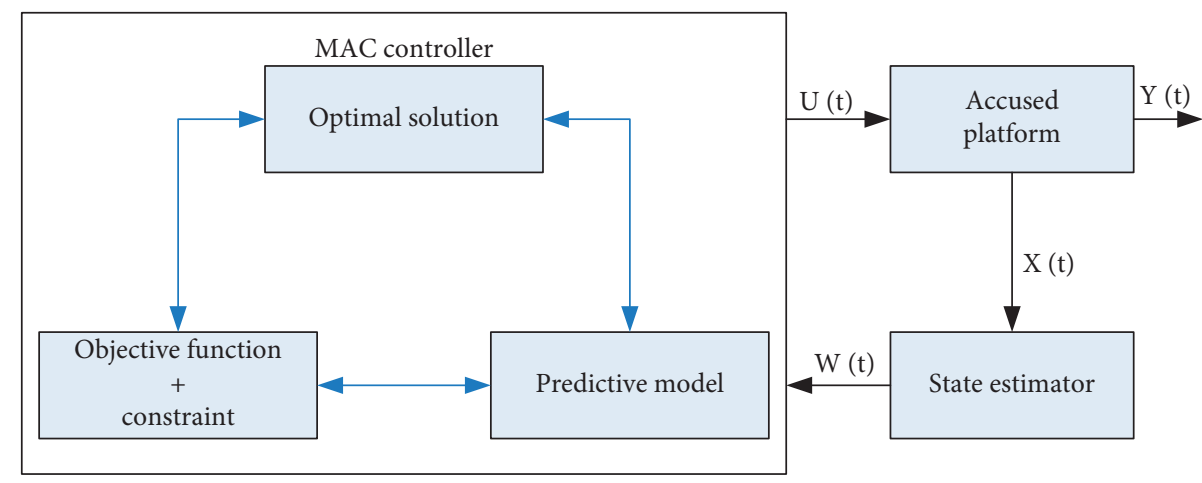

Figure 2: Control process.

into the state estimator, and the state estimator is fed back to the MPC controller for control at the next time [19].

\section{Simulation Experiment of the Hybrid Power System}

3.1. Composition of the Bench. The test bench of hybrid power system consists of three parts: powertrain, control system, and auxiliary part. The power assembly part mainly includes DEUTZ electronically controlled diesel engine, I-Axis motor M1 integrated with transmission I-Axis, II-axis motor M2 connected with transmission II-axis, AMT transmission, and lithium-ion power battery [20].

3.2. Power System Hardware Composition. The power module provides the UAV load with energy needed for flight. The control module is responsible for the energy scheduling, management, signal acquisition, and alarm protection of the system and obtains the power demand signal of the flight control system through the CAN bus and provides the power energy to the UAV load. The upper computer is responsible for real-time monitoring of the status information of the system in the debugging stage and storing and managing the system data [21, 22].

\subsection{Power System Software Process}

(1) SOC estimation: SOC of lithium battery is estimated by open circuit voltage method and ampere-hour integration method.

(2) Can communication: through communication with UAV flight control system to obtain UAV load required power.

(3) Energy management: the particle swarm optimization (PSO) algorithm is used to allocate the output power of fuel cells and lithium batteries. The power is obtained by querying the fuzzy control table stored offline.

(4) Wireless communication and data storage: the data is saved to the PC through the wireless transmission module and the data is saved to the local SD card $[23,24]$.
3.4. Power System Modeling. Engine model is the core component of hybrid power transmission system. The engine model in software is divided into theoretical modeling and experimental modeling. Theoretical modeling is to simulate the combustion of fuel by using the relevant knowledge of thermodynamics. The output torque and speed of the engine after energy conversion are usually idealized and static, and the modeling accuracy is relatively low [25]. The experimental modeling is to verify the performance of the engine on the premise that the engine model has been selected, that is, the actual output torque and speed from the combustion of fuel to the engine, and the fuel consumption rate of the engine is obtained through the calculation of relevant data, and the engine database is obtained by summarizing the obtained data. After obtaining the database, the dynamic model of the engine can be obtained by difference and fitting [26]. The dynamic model describes the system characteristics related to the operation time and sequence, the events that affect the change, the sequence of the events, the environment of the events, and the organization of the events. With the help of sequence diagrams, state diagrams, and activity diagrams, the dynamic model of the system can be described. Each diagram of the dynamic model helps to understand the behavioral characteristics of the system. For developers, dynamic modeling has the characteristics of clarity, visibility, and simplicity.

3.5. Optimization of Energy Management Strategies. The particle swarm optimization algorithm is written in .m file of MATLAB, and the dual source hybrid system model is built in MATLAB/Simulink environment. The particle swarm optimization (PSO) module calls the dual source hybrid system module through sim function and uses newfis, writefis, and other functions to create fuzzy controller and write parameters. At the same time, the dual source hybrid system module transfers the real-time value required by the optimization objective function to the particle swarm optimization algorithm .m file through the MATLAB workspace $[27,28]$.

3.6. Fuzzy Control. In this paper, the function of the fuzzy controller is summarized as optimizing the energy management and effectively improving the fuel efficiency of the 
system while meeting the load power demand. Fuzzy control mainly has the following steps:

(1) Fuzzification: the actual value input in the system is transformed into fuzzy quantity suitable for fuzzy control

(2) Fuzzy reasoning: fuzzy output is obtained by fuzzy decision-making through fuzzy rules [29]

(3) Antifuzzy processing: the fuzzy output is converted into the precise quantity that can be used in the control system through antifuzzy processing [30]

3.7. Energy Management Predictive Control. In this paper, GPS (Global Positioning System), GIS (Geographic Information System), and its (Intelligent Transportation System) information are used to obtain various vehicle speed, power, working conditions, and other information in the future, so as to make corresponding system preparation in advance. If the vehicle is currently driving on a straight road but is about to enter a long downhill, it can be predicted that the vehicle is about to enter a long downhill energy recovery state. Therefore, the energy of the accumulator can be appropriately released in advance to prepare for the full recovery of vehicle potential energy after the vehicle enters the road condition [31].

\section{Optimization Analysis of the Hybrid Power System}

4.1. Optimization Analysis of the Driving Mode of the Hybrid Power System. Table 1 shows the relationship between battery energy and vehicle quality for different pure electric distances. The voltage level of the battery is related to the peak power of the motor. The greater the peak power of the motor, the higher the voltage level of the power system, which is beneficial to ensure that the current does not exceed a certain limit, but an excessively high-voltage level can also cause high-voltage safety problems. Combined with the motor voltage level, the rated voltage of the power battery is determined to be $300 \mathrm{~V}$. Taking into account the efficiency and battery life and aging issues, the battery capacity is generally left with a margin of $30 \%$. The finally selected battery energy parameter is $9.8 \mathrm{kWh}$, which is composed of 24 modules. Taking into account the assembly factors such as the battery box, the weight of the whole vehicle becomes $2230 \mathrm{~kg}$. The reason for this phenomenon is that, on the one hand, with the increase of mixing degree, the increasing trend of recoverable braking energy in driving process slows down; on the other hand, although the increase of mixing degree improves the average working efficiency of engine, the increase of vehicle mass makes the total driving energy required by driving cycle increase.

Optimizing management strategies after determining the components of hybrid electric vehicles is the key to achieving low fuel consumption and low emission targets for hybrid electric vehicles. The management strategy of the hybrid power system must realize the reasonable and efficient distribution of energy between the engines according to the power requirements, emissions, and cost of the vehicle, so as to maximize the efficiency of the engine system and obtain the maximum fuel economy, the lowest emission, and stable driving performance according to the characteristics of various components and the operating conditions of the vehicle.

The NEDC cycle and required drive power are shown in Figure 3. It can be seen from the figure that the power required to overcome the acceleration resistance accounts for a large proportion in the four urban driving conditions with low vehicle speed. The maximum power demand in acceleration phase is $19.33 \mathrm{kw}$, and that in constant speed phase is $5.13 \mathrm{kw}$. At this time, due to the low total power demand, the engine will work in the noneconomic area if it is driven by the engine alone. Pure electric mode or driving charging mode can be used to shut down the engine or maintain the operating point of the engine in the economic area; in the suburban conditions, with the increasing of vehicle speed, the power required to overcome air resistance and friction resistance begins to occupy a dominant position, and the required driving power gradually increases, and the maximum power required in the constant speed stage is $36.92 \mathrm{kw}$. The maximum power demand in the acceleration phase is $55.51 \mathrm{kw}$. At this time, the vehicle power demand is in or above the engine economic area, so the engine driving mode or hybrid driving mode can be adopted to maintain the engine operating point in the economic area.

4.2. Battery SOC Optimization Effect. The change curve of battery SOC with time is shown in Figure 4 . The curve of energy consumption cost with time is shown in Figure 5. It can be seen from the figure that, in the early stage of simulation, the battery SOC decreases faster, uses more electric energy, and has lower energy consumption cost. Its immediate improvement energy management strategy is far superior to the global energy efficiency management strategy, and its cost will be lower. If the SOC of the battery drops by about 0.3 , its value will be balanced. The growth of energy costs has increased sharply, and energy costs have gradually exceeded the best overall energy management strategy. In the starting stage of the vehicle, the motor gives priority to work. When the vehicle decelerates and brakes, the battery SOC is kept in a relatively stable area, which is conducive to improving the service life and cycle times of the battery. Before the SOC value is reduced to $30 \%$, the whole vehicle runs in the power consumption stage, in which only pure electric drive mode is used. After 915 seconds of simulation, the operation mode is switched to the power holding stage. Both the logic threshold strategy and the fuzzy rule strategy can maintain the power consumption near the set switching threshold, and the power fluctuation is maintained in an appropriate range. Among them, the logic threshold strategy reaches the minimum value of $27.11 \%$ at $1165 \mathrm{~s}$, the maximum fluctuation of $3.49 \%$ in the power holding stage, the minimum value of $29.02 \%$ at $3486 \mathrm{~s}$, and the maximum fluctuation of $3.05 \%$ in the power holding stage. It can be seen that the two strategies have good SOC maintenance 
TABLE 1: The relationship between battery energy and vehicle quality for different pure electric distances.

\begin{tabular}{|c|c|c|c|c|c|c|c|c|}
\hline \multirow{2}{*}{$\begin{array}{l}\text { Working condition } \\
\text { Distance }(\mathrm{km})\end{array}$} & \multicolumn{4}{|c|}{ UDDS } & \multicolumn{4}{|c|}{ HWFET } \\
\hline & 12 & 24 & 36 & 48 & 16.5 & 33 & 50 & 66 \\
\hline Number of battery modules & 6 & 12 & 19 & 25 & 7 & 16 & 25 & 34 \\
\hline Battery energy (kWh) & 2.6 & 5.2 & 8.2 & 10.8 & 3.0 & 6.9 & 10.8 & 14.7 \\
\hline Vehicle mass $(\mathrm{kg})$ & 2093 & 2139 & 2192 & 2237 & 2101 & 2169 & 2237 & 2305 \\
\hline Battery SOC & 0.361 & 0.291 & 0.315 & 0.296 & 0.308 & 0.289 & 0.297 & 0.301 \\
\hline
\end{tabular}

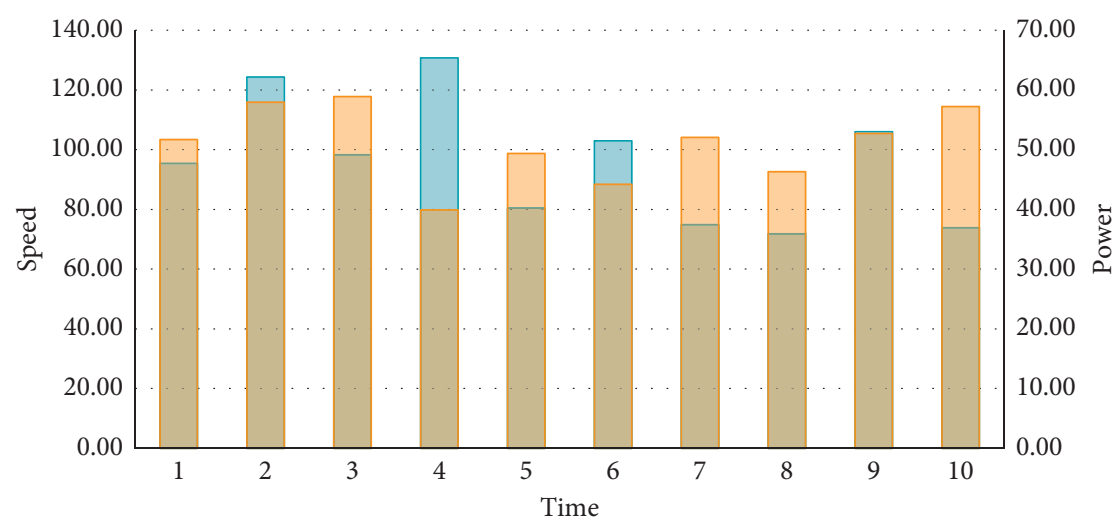

$\square$ NEDC speed

$\square$ Demand driving power

Figure 3: NEDC cycle conditions and required drive power.

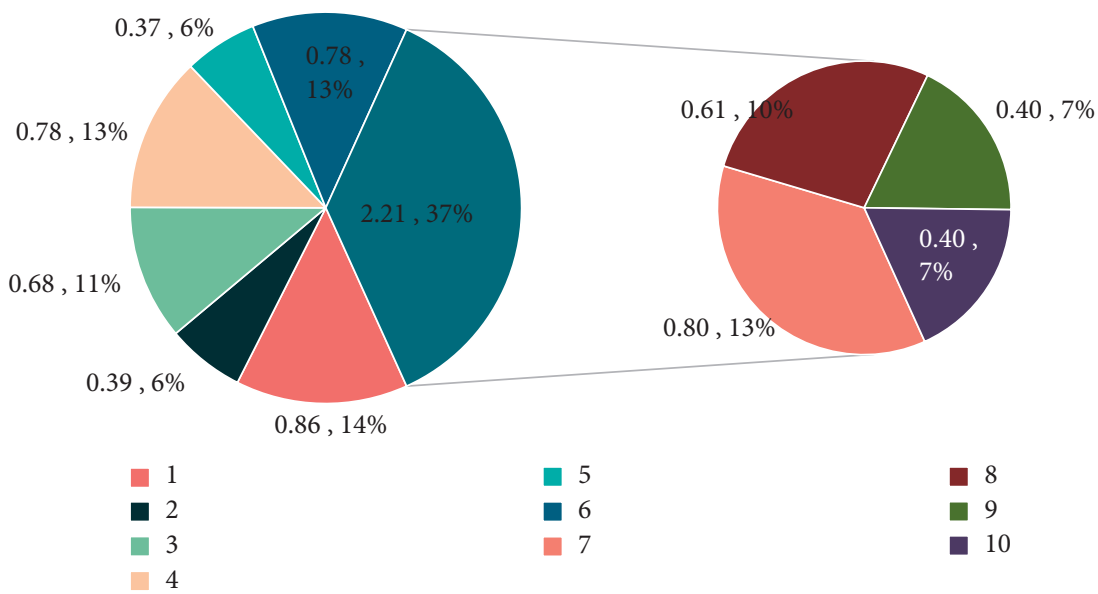

FIGURE 4: Battery SOC variation curve with time.

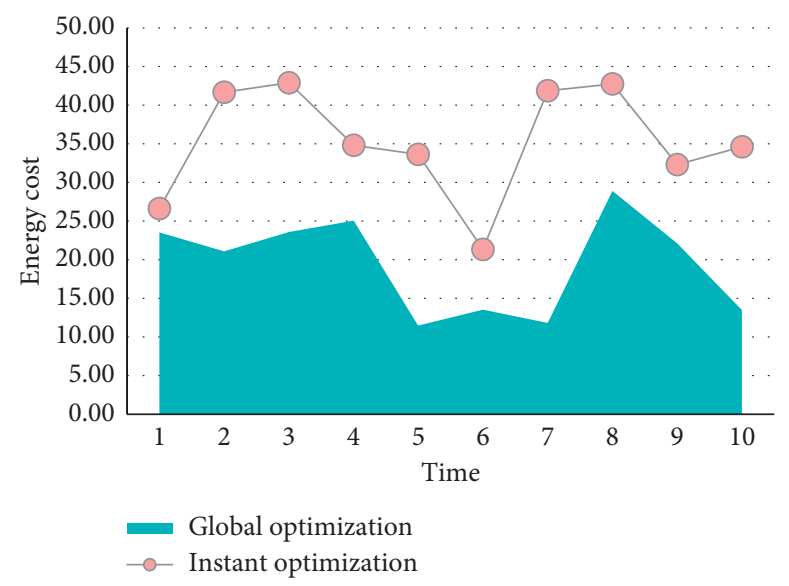

FIgURE 5: Energy consumption cost versus time curve. 
effect under NEDC cycle. At the end of the simulation, the SOC of logic threshold strategy is $29.81 \%$, and that of fuzzy rule strategy is $29.34 \%$.

Figure 4 proves the correctness of the above conclusions, but because the relationship between it and Figure 5 is too close, we directly combine the two to discuss them. Basically, Figure 5 is a deepening of Figure 4. We follow Figure 4 in the logic of Figure 5 and Figure 5 can well indicate the content and conclusions of the follow-up research. The specific results can be seen in Figure 5.

The driving force required by the whole vehicle is calculated at each time step according to the speed required by the cycle, and the driving force is converted into driving torque, which is inversely calculated along the direction opposite to the actual vehicle torque transmission route. The controller uses the energy management control strategy in advance to distribute the required power of the whole vehicle from the transmission components and then transfers the target demand value to the power source to realize the control process. The power source outputs the working torque according to the current working state and the controller demand command.

When braking, if the vehicle speed is higher than the minimum speed limit of braking energy recovery, the braking energy recovery mode will be started. The data and curve of braking energy recovery in a certain section are shown in Table 2 and Figure 6. When the PHEV vehicle controller receives the brake pedal signal at $4.5 \mathrm{~s}$, the system changes from hybrid drive mode to braking energy recovery mode, and the motor changes to generator mode. In the $8 \mathrm{~s}$, the speed of motor and engine drops to $600 \mathrm{r} / \mathrm{min}$, the engine is unstable in this speed range, and the motor efficiency is low. Therefore, the clutch is released and the subsequent braking process is completed by friction braking system independently.

From Figure 6, we can know the following information. The energy recovery curve represents some control nodes. They are an important criterion for the conversion of the motor to the generator mode. The development of the curve directly represents whether the friction system can independently complete the conversion of the power system.

4.3. System Compatibility Analysis. During the PHEV fuel economy experiment, according to the hybrid electric vehicle energy consumption test method, the gas consumption in the cylinder and battery SOC before and after the experiment were recorded at the same time. According to the requirements of the national standard, the fuel economy experiment was carried out 3 times, and the obtained 3 experiments' data was averaged as the final test result. The results of the three experiments' data are shown in Table 3 and Figure 7. From the data in the table, we can see that the total fuel consumption of the three sets of experiments is averaged to get the fuel consumption rate of the hybrid city bus under the optimized energy management strategy of $26.3 \mathrm{~m}^{3} / 100 \mathrm{~km}$. In order to verify the effect of the optimized energy management strategy based on PMP, a set of comparative experiments was carried out. The specific experimental steps are basically the same as the abovementioned economic experiments. Compared with the energy management strategy based on definite rules, the economic performance of the proposed PMP-based optimized energy management strategy is improved by $18 \%$.

We can know from Figure 7 that the figure tells us that $\mathrm{SOH}$ will gradually decrease, which is caused by its loss during use. Of course, it is not only human factors, living environment, soil, and air. Many factors can deplete the battery. When the battery decays to the point of irreversibility, it will eventually reach the lifespan. Upon termination, the $\mathrm{SOH}$ of the battery will become $0 \%$. The change curve of the battery $\mathrm{SOH}$ in the 3000-day service cycle is shown in Figure 8. In the implemented precise logic control strategy, the discharge rate of the battery is a fixed threshold. The attenuation of the battery is a constantly occurring process. Obviously, when a fixed power threshold is always used to limit the charge and discharge of the battery, it will make the battery charge and discharge rate unable to be maintained all the time. It is necessary to adjust the threshold value in the energy management strategy in conjunction with $\mathrm{SOH}$, so that the threshold value is in the process of dynamic adjustment, and the economy of the vehicle and the attenuation of the battery are well controlled.

4.4. Energy Management Strategies. If the fuel cell is used as the only power source, the transient response speed of the fuel cell is slow, and the vehicle cannot accurately provide the required energy during rapid start, emergency acceleration, and climbing. In addition, the fuel cell is a unidirectional power source and cannot recover braking energy. When designing the fuzzy controller, it is necessary to continuously test and improve the hybrid power system using fuzzy control strategy rules. The criterion for the control effect is whether the fuel consumption value is reduced and whether the emission of various gases is reduced. The fuel consumption results of CD/CS strategy, dynamic planning strategy, and fast energy management strategy are shown in Table 4 . The rapid energy management strategy can achieve fuel consumption similar to the dynamic planning strategy. The difference in fuel consumption under different measured conditions is $0.79 \%, 0.03 \%, 0.33 \%$, and $0.94 \%$, respectively.

Compared with the original vehicle, any control strategy can get good fuel economy, among which the control strategy based on simple rules has poor effect, and ECMs control effect is the best. The control effect of fuzzy logic is related to a large amount of experimental data and expert knowledge, and different control objectives can also form different control effects, which is more flexible. The SOC curves of fast energy management strategy and dynamic planning strategy and the SOC difference between them are shown in Figures 9 and 10. It can be seen from the figure that the SOC curves of the two are very similar, and the difference is within $3 \%$. It can be seen from the figure that the power of SOFC cannot meet the load demand in the startup stage within 1000 s. Lithium battery, as an auxiliary energy storage element, can quickly supplement the lack of power of DC 
TABLE 2: Brake energy recovery data.

\begin{tabular}{lllllllllll}
\hline Motor speed & 468.34 & 425.94 & 270.79 & 248.34 & 345.49 & 540.11 & 261.63 & 489.03 & 454.60 & 533.80 \\
Engine speed & 484.36 & 304.41 & 412.49 & 460.21 & 543.27 & 447.37 & 322.90 & 775.82 & 641.41 & 559.06 \\
Vehicle speed & 698.53 & 861.81 & 483.55 & 397.25 & 542.67 & 727.49 & 793.72 & 848.07 & 669.10 & 833.69 \\
\hline
\end{tabular}

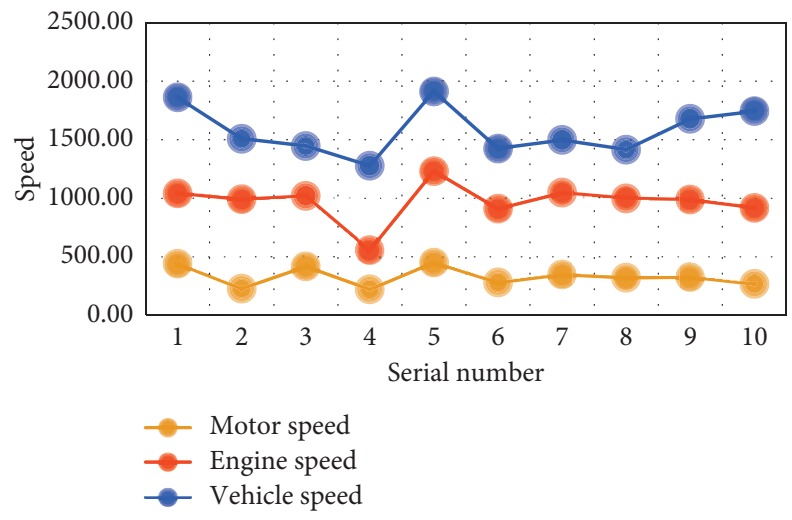

FIgURE 6: Braking energy recovery curve.

TABle 3: Data statistics of vehicle economy experiment.

\begin{tabular}{lccc}
\hline Name & Experiment 1 & Experiment 2 & Experiment 3 \\
\hline Actual gas consumption & 19.3 & 19.0 & 19.9 \\
Actual power consumption & 19.5 & 19.8 & 20.1 \\
Total fuel consumption & 26.1 & 25.9 & 26.9
\end{tabular}

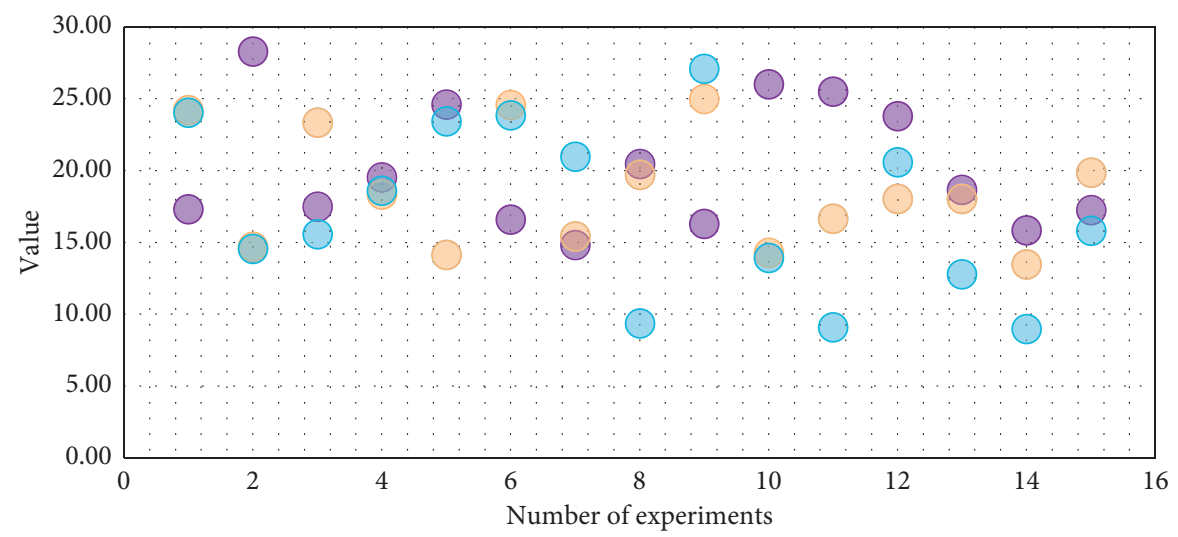

Actual gas consumption

- Actual power consumption

- Total fuel consumption

Figure 7: Comparison of results of experimental data.

bus, so that the output power of the whole system can meet the demand of the load. After $1000 \mathrm{~s}$, SOFC has entered the stage of on-load power generation, but its output power fluctuates greatly. The output power is controlled in a stable state through the continuous switching of charge and discharge state of lithium battery and SOFC. 


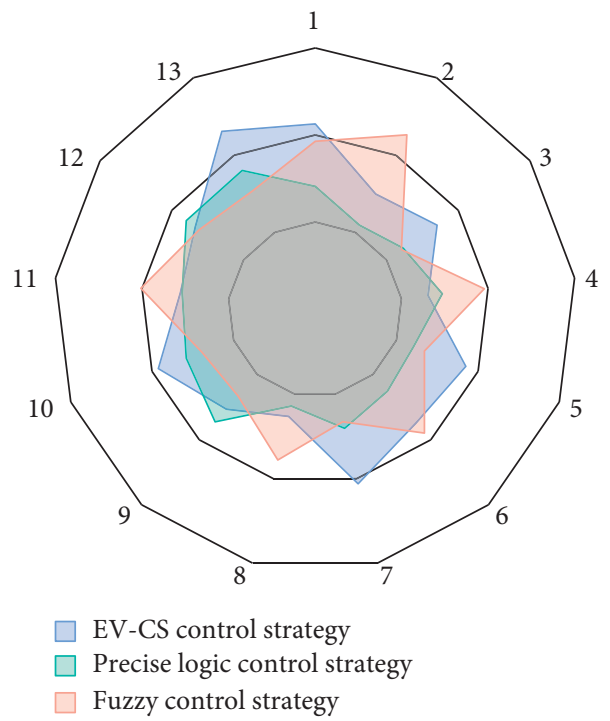

FIGURE 8: The change curve of battery SOH in a 3000-day life cycle.

TABLE 4: Fuel consumption results of CD/CS strategy, dynamic planning strategy, and fast energy management strategy.

\begin{tabular}{lccc}
\hline Energy management strategy & Equivalence factor & Terminal SOC (\%) & Fuel consumption (kg) \\
\hline CD/CS strategy & 3.55 & 30.26 & 0.7165 \\
Fast energy management & 3.02 & 29.96 & 0.6847 \\
Dynamic programming & 2.78 & 30.90 & 0.6968 \\
\hline
\end{tabular}

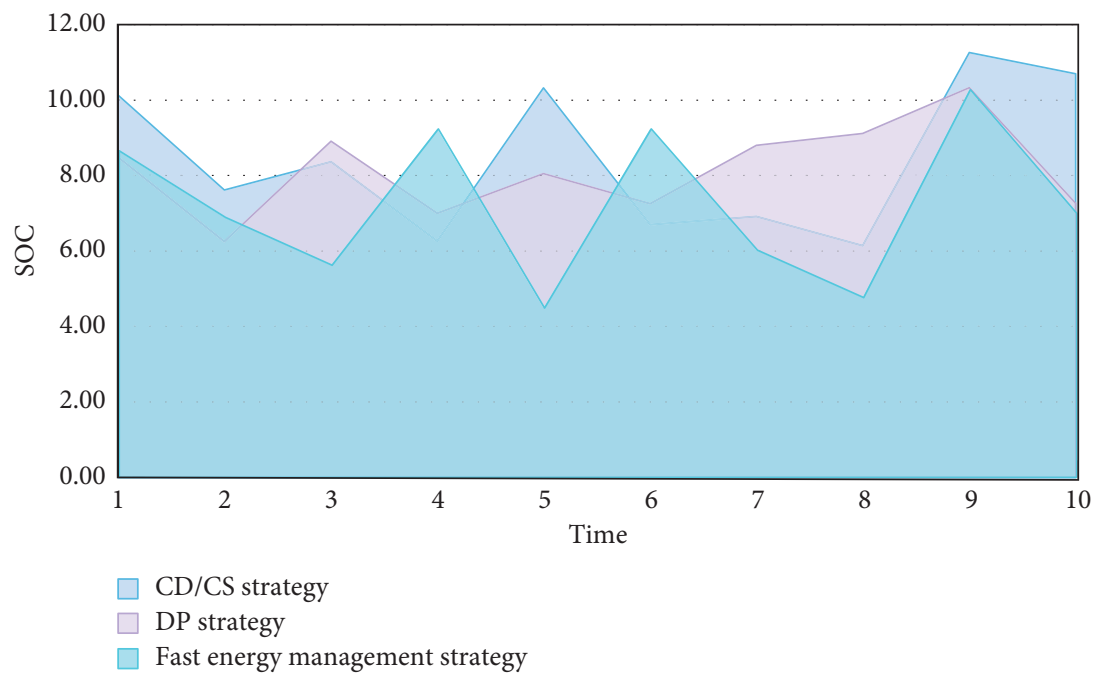

Figure 9: SOC curve. 


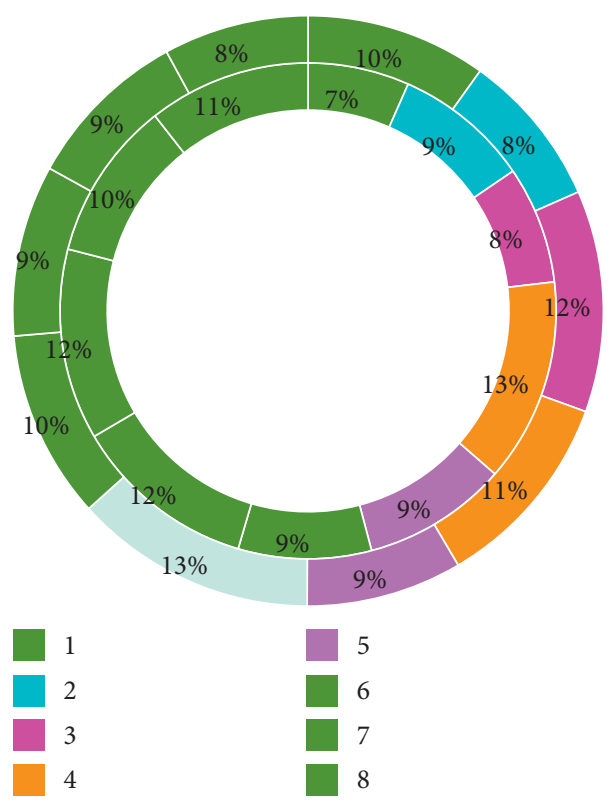

FIGURE 10: SOC difference.

\section{Conclusions}

This paper mainly studies the real-time application optimization control algorithm of the energy management strategy of the hybrid power system based on artificial intelligence. This paper analyzes the energy consumption of hybrid electric vehicle (HEV) from the whole point of view, introduces a new equivalent factor, and establishes the relationship between battery energy consumption and fuel consumption energy. The energy management strategy includes the optimal shift strategy and the optimal torque allocation strategy. Given the driving cycle, the energy management problem of $\mathrm{HEV}$ is modeled as a multistep decision process problem. The global optimal results and corresponding control trajectories can be obtained by using the dynamic programming theory. Therefore, the dynamic programming method can be used as a benchmark to measure the control effect of other energy management strategies.

Maximum value principle and dynamic programming study theoretically the equations and conditions that the optimal control should follow, while the optimal control algorithm is to determine the specific methods and steps of the optimal control form the calculation aspect (see the optimization method). On the whole, the optimal control algorithm can be divided into two categories: indirect method and direct method. For a given type of control problem, the optimal control theory can derive the conditions and equations used to determine the optimal control, and the solution can be obtained by related calculation methods. This type of method is called indirect method. For a class of problems in which it is difficult to determine the optimal control conditions and equations, numerical methods must be used to directly find their approximate solutions. This type of method is called direct method. Either the indirect method or the direct method can help in the real-time application of hybrid power system energy management strategies.
Through the calculation of the parameters of the whole locomotive, the input power of traction inverter and the parameter configuration of traction motor are determined under three different operating states of the locomotive, namely, the maximum speed, the maximum gradient, and the maximum acceleration. The parameter matching of fuel cell hybrid power system is completed by combining the efficiency and economic cost of fuel cell and lithium battery. Through the construction of dynamic model of fuel cell, the dynamic module of PEM fuel cell is simulated. The voltage of fuel cell corresponding to different input current is obtained, and the linear analysis of fuel cell is realized.

According to the different working modes of the power system, the working mode conversion conditions and power distribution are determined, and the vehicle control strategy model is established by using MATLAB/Stateflow. In order to reduce fuel consumption, particle swarm optimization (PSO) is used to discuss the threshold value of engine switch and the output mechanical power of motor under the electric auxiliary strategy. Starting from the specific driving distance and constant speed conditions, the better combination under different power requirements is obtained. The fuzzy torque distribution controller, which is optimized according to various working conditions, controls the output torque of the engine motor according to the required torque of the hybrid power system and the state of charge of the battery pack. After the theoretical knowledge is enriched, our research results can also prove that the different combinations obtained by studying the speed can well verify the needs of this article. These combinations are the optimal solutions for hybrid power systems and energy management strategies.

\section{Data Availability}

No data were used to support this study. 


\section{Conflicts of Interest}

The authors declare no conflicts of interest.

\section{Acknowledgments}

This work was supported by Jilin Province Science and Technology Development Plan Project (20190303117SF): Research and Application of Mineral Resources Prediction Method Based on Nonlinear Theory.

\section{References}

[1] K. Ettihir, L. Boulon, and K. Agbossou, "Optimization-based energy management strategy for a fuel cell/battery hybrid power system," Applied Energy, vol. 163, no. 2, pp. 142-153, 2016.

[2] J. Cao, Z. Yan, X. Xu, G. He, and S. Huang, "Optimal power flow calculation in AC/DC hybrid power system based on adaptive simplified human learning optimization algorithm," Journal of Modern Power Systems and Clean Energy, vol. 4, no. 4, pp. 690-701, 2016.

[3] N. Bizon, J. M. Lopez-Guede, E. Kurt et al., "Hydrogen economy of the fuel cell hybrid power system optimized by air flow control to mitigate the effect of the uncertainty about available renewable power and load dynamics," Energy Conversion and Management, vol. 179, no. 1, pp. 152-165, 2019.

[4] T. Mahto and V. Mukherjee, "A novel scaling factor based fuzzy logic controller for frequency control of an isolated hybrid power system," Energy, vol. 130, no. 7, pp. 339-350, 2017.

[5] X. Yang, H. Li, L. Ni, and T. Li, "Application of artificial intelligence in precision marketing," Journal of Organizational and End User Computing, vol. 33, no. 4, 2021.

[6] T. Alnejaili, S. Drid, D. Mehdi, and L. Chrifi-Alaoui, "A developed energy management strategy for a stand-alone hybrid power system for medium rural health building," International Transactions on Electrical Energy Systems, vol. 26, no. 4, pp. 713-729, 2016.

[7] G. Shankar and V. Mukherjee, "Load frequency control of an autonomous hybrid power system by quasi-oppositional harmony search algorithm," International Journal of Electrical Power and Energy Systems, vol. 78, no. 6, pp. 715-734, 2016.

[8] A. Mohamed Abd el Motaleb, S. Kazim Bekdache, and L. A. Barrios, "Optimal sizing for a hybrid power system with wind/energy storage based in stochastic environment," Renewable and Sustainable Energy Reviews, vol. 59, no. 6, pp. 1149-1158, 2016.

[9] N. K. Saxena and A. Kumar, "Cost based reactive power participation for voltage control in multi units based isolated hybrid power system," Journal of Electrical Systems and Information Technology, vol. 3, no. 3, pp. 442-453, 2016.

[10] S. Baudoin, I. Vechiu, H. Camblong, J.-M. Vinassa, and L. Barelli, "Sizing and control of a solid oxide fuel cell/gas micro turbine hybrid power system using a unique inverter for rural microgrid integration," Applied Energy, vol. 176, no. 8 , pp. 272-281, 2016.

[11] A. Modirkhazeni, O. N. Almasi, and M. H. Khooban, "Improved frequency dynamic in isolated hybrid power system using an intelligent method," International Journal of Electrical Power and Energy Systems, vol. 78, no. 6, pp. 225-238, 2016.
[12] M. Combe, A. Mahmoudi, M. H. Haque, and R. Khezri, "Optimal sizing of an AC-coupled hybrid power system considering incentive-based demand response," IET Generation, Transmission and Distribution, vol. 13, no. 15, pp. 3354-3361, 2019.

[13] S. Z. Hassan, H. Li, T. Kamal, M. J. E. Trujillo, and B. Cevher, "Load sharing and arrangement through an effective utilization of SOFC/Super-capacitor/Battery in a hybrid power system," Iranian Journal of Science and Technology, Transactions of Electrical Engineering, vol. 43, no. 2, pp. 383-396, 2019.

[14] F. Mirzapour, M. Lakzaei, G. Varamini, M. Teimourian, and N. Ghadimi, "A new prediction model of battery and windsolar output in hybrid power system," Journal of Ambient Intelligence and Humanized Computing, vol. 10, no. 1, pp. 77-87, 2019.

[15] M. B. Othman, N. P. Reddy, P. Ghimire, M. K. Zadeh, A. Anvari-Moghaddam, and J. M. Guerrero, "A hybrid power system laboratory: testing electric and hybrid propulsion," IEEE Electrification Magazine, vol. 7, no. 4, pp. 89-97, 2019.

[16] A. Tabanjat, M. Becherif, D. Hissel, and H. S. Ramadan, "Energy management hypothesis for hybrid power system of H 2/WT/PV/GMT via AI techniques," International Journal of Hydrogen Energy, vol. 43, no. 6, pp. 3527-3541, 2018.

[17] R. P. Narasipuram, "Optimal design and analysis of hybrid photovoltaic-fuel cell power generation system for an advanced converter technologies," International Journal of Mathematical Modelling and Numerical Optimisation, vol. 8, no. 3, pp. 245-276, 2018.

[18] G. Yang, A. Zhang, S. Li et al., "Multi-objective evolutionary algorithm based on decision space partition and its application in hybrid power system optimisation," Applied Intelligence, vol. 46, no. 4, pp. 827-844, 2017.

[19] A. G. Shaik and O. P. Mahela, "Power quality assessment and event detection in hybrid power system," Electric Power Systems Research, vol. 161, no. 8, pp. 26-44, 2018.

[20] R. Yousefian and S. Kamalasadan, "A Lyapunov function based optimal hybrid power system controller for improved transient stability," Electric Power Systems Research, vol. 137, no. 8, pp. 6-15, 2016.

[21] F. Yang and X. Xia, "Techno-economic and environmental optimization of a household photovoltaic-battery hybrid power system within demand side management," Renewable Energy, vol. 108, no. 8, pp. 132-143, 2017.

[22] G. Magdy, E. A. Mohamed, G. Shabib, A. A. Elbaset, and Y. Mitani, "SMES based a new PID controller for frequency stability of a real hybrid power system considering high wind power penetration," IET Renewable Power Generation, vol. 12, no. 11, pp. 1304-1313, 2018.

[23] C. Wu, J. Chen, C. Xu, and Z. Liu, "Real-time adaptive control of a fuel cell/battery hybrid power system with guaranteed stability," IEEE Transactions on Control Systems Technology, vol. 25, no. 4, pp. 1394-1405, 2017.

[24] R. K. De and A. Ganguly, "Energy, exergy and economic analysis of a solar hybrid power system integrated doubleeffect vapor absorption system-based cold storage," International Journal of Air Conditioning and Refrigeration, vol. 27, no. 2, pp. 115-124, 2019.

[25] B. Xu, D. Chen, M. Venkateshkumar et al., "Modeling a pumped storage hydropower integrated to a hybrid power system with solar-wind power and its stability analysis," Applied Energy, vol. 248, no. 8, pp. 446-462, 2019.

[26] F. Yiwei, L. Zongxiang, H. Wei et al., "Research on joint optimal dispatching method for hybrid power system 
considering system security," Applied Energy, vol. 238, no. 3, pp. 147-163, 2019.

[27] W. Song, S. Li, L. Du, W. Lin, L. Cui, and J. Yao, "Low rank coal pyrolysis poly-generation and hybrid power system," The Chinese Journal of Process Engineering, vol. 18, no. 5, pp. 893-899, 2018.

[28] M. Gökçek and C. Kale, "Techno-economical evaluation of a hydrogen refuelling station powered by Wind-PV hybrid power system: a case study for İzmir-Çeşme," International Journal of Hydrogen Energy, vol. 43, no. 23, pp. 10615-10625, 2018.

[29] B. Nithiya and R. Eswari, "Efficient VM selection strategies in cloud datacenter using fuzzy soft set," Journal of Organizational and End User Computing, vol. 33, no. 5, 2021.

[30] F.-F. Li, J. Qiu, and J.-H. Wei, "Multiobjective optimization for hydro-photovoltaic hybrid power system considering both energy generation and energy consumption," Energy Science and Engineering, vol. 6, no. 5, pp. 362-370, 2018.

[31] N. Arnaoutakis, F. Kanellos, and S. Papaefthimiou, "Combined operation, modeling and life cycle assessment of a generic hybrid power system installed in Crete," Energy systems, vol. 9, no. 2, pp. 343-359, 2018. 